\title{
AVALIAÇÃO CLINICA E CIRÚRGICA DE GINECOMASTIA EM PACIENTES DO SUS
}

\author{
Darley de Lima Ferreira Filho', Nancy Cristina Ferraz de Lucena Ferreira1, Thais de Lucena Ferreira² \\ ${ }^{1}$ Hospital Barão de Lucena - Recife (PE), Brazil. \\ ${ }^{2}$ Faculdade Pernambucana de Saúde - Recife (PE), Brazil.
}

Introduction: The incidence of gynecomastia in the population is still unknown. However, there are peaks of incidence in the newborn between 60-90\% have a transient development, during puberty approximately 10 years of age and with the highest peak between 13 and 14 years of age and in the adult population, with prevalence increased from approximately 50 years old and continues through the eighth decade of life. According to Webster, it occurs in 8 for every 100.00 individuals. Responsible for $65 \%$ of benign pathologies in man. Objective: To evaluate the epidemiological and clinical characteristics and the most used types of surgery, as well as its aesthetic results and complications. Methods: A prospective, observational study was carried out at the Mastology and Breast Reconstruction service of the Barão Lucena Hospital in 40 patients from April 2016 to April 2017. Patients were clinically examined at the outpatient clinic, at the request of hormonal exams in some cases, with mammography and ultrasound imaging, where the following variables were analyzed: origin, education level, age, personal history, gynaecomastia degree, type of surgery, complications, and aesthetic result. Results: 40 patients were studied over a one-year period. We observed that more than 24 (60\%) of our patients came from the metropolitan region of our state, followed by 14 (35\%) from the interior and 2 (5\%) from other Northeastern states. Gynaecomastia at puberty were found in 18 (45\%) patients, followed by $8(20 \%)$ of the patients, followed by the upper level in 10 patients $(25 \%)$ and retired in $6(15 \%)$ in the age group of 21 to 30 years. There were also $8(20 \%)$ patients identified in the group over 50 years old. It was not evidenced in 27 (67.5\%) of the previous patients the risk factors that could lead to the development of gynecomastia. However, drug use accounted for $20 \%$, and use of drugs for hypertension, cancer, antidepressants, and HIV (12.5\%). The most used surgery in our service was double-circle in 21 patients (52\%), followed by periareolar-Weeter in 14 patients (35\%) and transareolopapillary (Pitangy) in 4 patients (10\%). We had one case when it was necessary to perform mastectomy with free graft of the areolo-papillary complex. The type of surgery is very much in agreement with the degree of gynecomastia found, where type 3 was evident in $45 \%$, followed by type 1 with $25 \%$, and type 2 with $25 \%$. Type 4 was found in only $5 \%$. Our patients had an average of 24 hours of hospital admission. After analysis of the type of surgery and gynecomastia, the next item to be evaluated were complications, where the vast majority of patients had no complications in $62 \%$ of cases, but seroma formation and hematoma were found in $30 \%$. A late complaint of the patients was with regard to the surgical scar, which is a factor to be explained to the patients before the procedure. Another factor of extreme importance and with regard to patient satisfaction in relation to the final result, more than $80 \%$ of them considered between good and good, respectively, after return to the outpatient clinic and follow up for a period of 6 months. However, gynecomastia is a pathology with a strong social impact. This could be observed after analyzing the clinical and surgical characteristics of our patients. Surgery proved to be the main option for this type of pathology and demonstrated a very high degree of patient satisfaction. 